\title{
Comparative study to assess the maternal and paternal fetal attachment among the expectant mothers and fathers
}

\author{
Sarabjit Kaur*, Mamta, Nidhi Sagar
}

Department of Nursing, College of Nursing, Dayanand Medical College and Hospital, Ludhiana, Punjab, India

Received: 15 May 2017

Accepted: 10 June 2017

*Correspondence:

Dr. Sarabjit Kaur,

E-mail: sarabsandhu1291@gmail.com

Copyright: () the author(s), publisher and licensee Medip Academy. This is an open-access article distributed under the terms of the Creative Commons Attribution Non-Commercial License, which permits unrestricted non-commercial use, distribution, and reproduction in any medium, provided the original work is properly cited.

\begin{abstract}
Background: Bonding during pregnancy refers to a process through which a pregnant women experiences feelings and emotions for her fetus, interacts with her fetus and develops a maternal identity during pregnancy. The mothers and fathers interact differently with the developing fetus, but evidences for these differences are contradictory. It is important to recognize the factors influencing maternal fetal attachment and paternal fetal attachment because of the effects on future health and development of the infant.

Methods: A descriptive (comparative) research design was used to compare the maternal and paternal fetal attachment among 50 couples [Expectant mothers (50) and Expectant fathers $(50)=100$ ] selected by convenience sampling technique, who visited ANC OPD of DMC and Hospital, Ludhiana, Punjab. Modified Maternal Fetal Attachment Scale (Mecca S Cranley, 1979) and Modified Paternal Fetal Attachment Scale (Mecca S Cranley, 1979) were used to assess the maternal and paternal fetal attachment by self-report method.

Results: Findings revealed that the maternal fetal attachment was higher than the paternal fetal attachment. There was significant difference between maternal and paternal fetal attachment scores $(89.76 \pm 13.410$ vs $80.62 \pm 15.494$, $\mathrm{p}=0.002$ ) respectively. The association of maternal fetal attachment was found to be statistically significant with gravida, parity, live babies, planned pregnancy, history of infertility, method of conception and marital relationship $(\mathrm{p}<0.05)$ whereas paternal fetal attachment was found to be statistically significant with duration of marriage, number of live children and method of conception $(\mathrm{p}<0.05)$.
\end{abstract}

Conclusions: Thus, the study concluded that the maternal fetal attachment was higher than paternal fetal attachment.

Keywords: Attachment, Maternal fetal attachment, Paternal fetal attachment

\section{INTRODUCTION}

Having a baby is a great evolutionary change for both men and women who are experiencing being father and mother. It is a special and emotional time for both of them. The connection between the expectant mother and father with the unborn baby is the most important and mysterious relationship. ${ }^{1}$ Bonding with a baby during pregnancy refers to a process through which a pregnant woman and her partner experience feelings and emotions for their fetus, interacts with their fetus and develop a maternal identity (i.e. begins to identify herself as a mother) and paternal identity (begins to identify himself as a father) during pregnancy. ${ }^{2}$ The bond between a woman and her fetus is often conceptualizing by health professionals in terms of maternal fetal attachment and bond with the men and his fetus in terms of paternal fetal attachment. ${ }^{3}$ Maternal Fetal Attachment and Paternal Fetal Attachment play an important role in the health of pregnant women and their unborn babies. ${ }^{4}$ However, both the mother and father are attached to the fetus when expecting a baby. Mothers and fathers interact differently 
with the developing fetus, but evidence for these differences is contradictory. ${ }^{5}$

The objective of present study was to assess and compare the maternal and paternal fetal attachment among the expectant mothers and fathers and to find out the association of maternal and paternal fetal attachment with selected socio demographic variables.

\section{METHODS}

Descriptive (comparative) research design was used to assess the maternal and paternal fetal attachment among the expectant mothers and fathers visiting ANC OPD of a DMC and Hospital, Ludhiana, Punjab. The study was carried out on 50 couples [Expectant mothers (50) and Expectant fathers $(50)=100]$ selected by convenience sampling technique over a period of 1 month. Modified Maternal Fetal Attachment Scale (Mecca S Cranley, 1979) and Modified Paternal Fetal Attachment Scale (Mecca S Cranley, 1979) were used to assess the maternal and paternal fetal attachment by paper pencil method. Inclusion criteria: Expectant mothers and fathers who were visiting ANC OPD at the time of data collection, in the third trimester of the pregnancy, willing to participate and able to read and write in Hindi, Punjabi and English. Exclusion criteria: Expectant mothers and fathers who were visiting ANC OPD without their partner.

\section{RESULTS}

Table 1 shows comparison of maternal and paternal fetal attachment among expectant mothers and fathers. It was revealed that the expectant mothers had higher fetal attachment mean scores $(92.66 \pm 13.48)$ than the expectant fathers $(80.62 \pm 15.494)$. Therefore, there was statistically significant mean difference between two groups.

Hence, it can be concluded that the maternal fetal attachment is more than paternal fetal attachment because mothers are the carriers and feels fetus more closely.

Table 1: Comparison of maternal and paternal fetal attachment among expectant mothers and fathers.

\begin{tabular}{|llllll|}
\hline Variables & Group & N & Mean \pm SD & Mean $(\%)$ & t-test statistics \\
\multirow{2}{*}{ Attachment } & Expectant mothers & 50 & $92.66 \pm 13.483$ & 74.128 & 4.145 \\
& Expectant fathers & 50 & $80.62 \pm 15.494$ & 64.496 & $\mathrm{df}=98, \mathrm{p}=0.000 *$ \\
\hline
\end{tabular}

Max. score $=125 ;$ Min. score $=25 ; *$ Significant at $p<0.05 ;$ NS: Non-significant $p>0.05$.

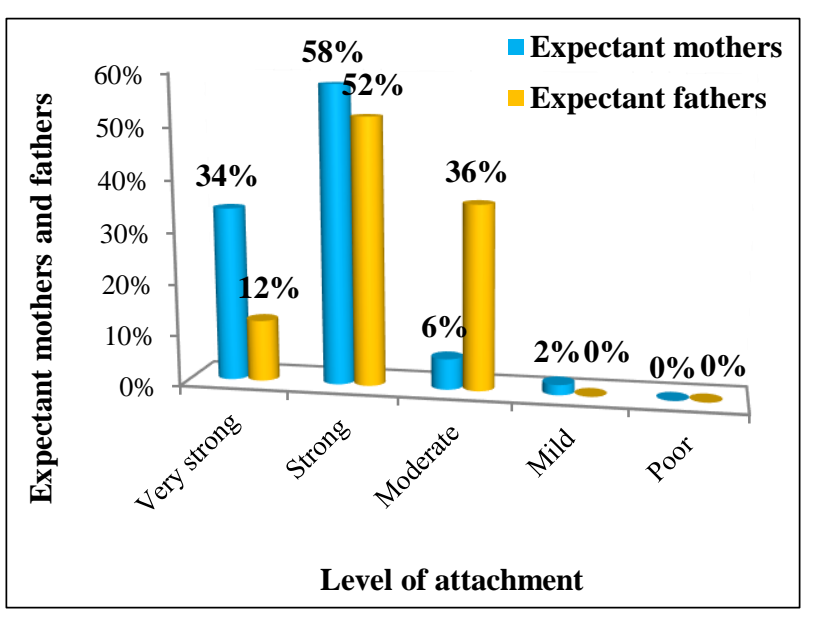

Mean score of expectant mothers $=92.66 \pm 13.483$; Mean score of expectant fathers $=80.62 \pm 15.494$

\section{Figure 1: Comparison of expectant mothers and fathers as per level of attachment.}

Figure 1 illustrates the comparison of expectant mothers and fathers as per level of attachment. It shows that $34 \%$ of the expectant mothers and $12 \%$ of the expectant fathers had very strong level of attachment, $58 \%$ of the expectant mothers and $52 \%$ of the expectant fathers had strong level of attachment, $6 \%$ of the expectant mothers and $36 \%$ of the expectant fathers had moderate level of attachment and only $2 \%$ of the expectant mothers but no expectant father had mild level of attachment with the fetus. None of the expectant mother and father had poor level of attachment with their fetus. So, it is concluded that the majority of the expectant mothers and fathers had strong level of attachment.

Figure 2 shows that the expectant mothers had higher mean \% (82.16) in Role taking, followed by (76.8) in Interaction with fetus, (75.2) in Differentiation of self from fetus, (69.6) in Giving of self and (68.16) in Attributing characteristics to the fetus whereas expectant fathers had higher mean \% (71.28) in Role taking, followed by (67.92) in Interaction with fetus, (64.3) in Giving of self, (59.8) in Differentiation of self from fetus and (46) in Attributing characteristics to the fetus. Therefore, it revealed that both the expectant mothers and fathers had higher mean $\%$ in component role taking as they were very well aware regarding their maternal and paternal role.

The association of maternal fetal attachment was found to be statistically significant with Gravida $(\mathrm{p}=0.008)$, parity $(\mathrm{p}=0.0001)$, live birth $(\mathrm{p}=0.0001)$, gender of previous 
child $(\mathrm{p}=0.0001)$, planned pregnancy $(\mathrm{p}=0.0001)$, history of infertility $(p=0.004)$, method of conception $(p=0.023)$ and marital relationship $(\mathrm{p}=0.002)$ except abortion and duration between marriage and conception and number of still births $(p>0.05)$. The association of paternal fetal attachment with paternal profile.

There was statistically significant association of paternal fetal attachment with number of live children (0.0001), gender of previous child (0.0001) and method of conception (0.021) whereas planned pregnancy, history of infertility and duration between marriage and conception were found to be non-significant as ( $p>0.05)$.

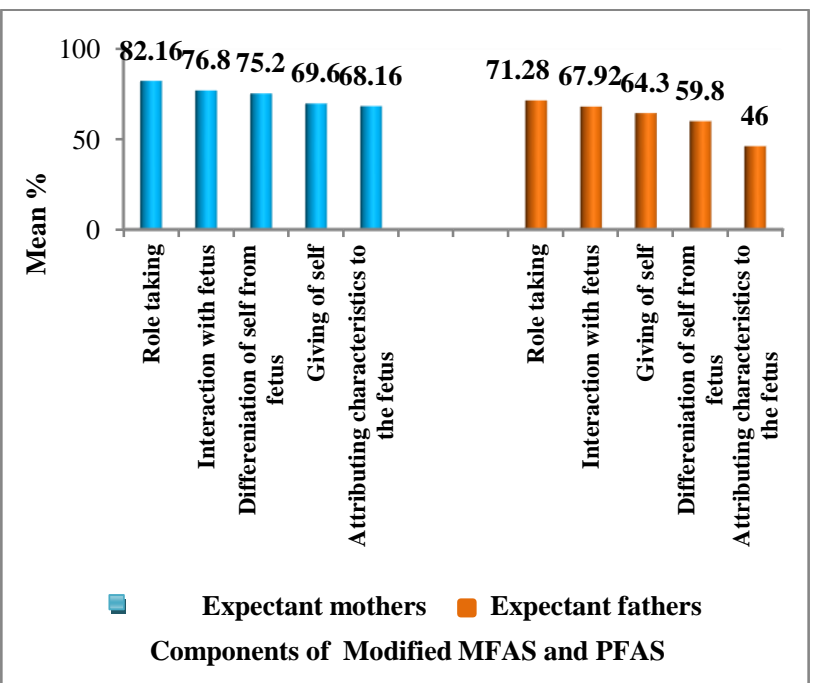

Maximum attachment score $=125$; Minimum attachment score $=25$; Mean score of expectant mothers $=92.66 \pm 13.483$ (Mean $\%=74.12$ ); Mean score of expectant fathers $=80.62 \pm 15.494$ (Mean \%=64.49).

\section{Figure 2: Rank wise distribution of components of} components of modified MFAS and PFAS.

\section{DISCUSSION}

A comparative study was conducted to assess the maternal and paternal fetal attachment among 50 expectant mothers and 50 expectant fathers (couples). The major findings of the study showed that expectant mothers had more fetal attachment than paternal fetal attachment in expectant fathers as per their mean difference. Mean percentage of expectant mothers $(74.128 \%)$ and expectant fathers $(64.496 \%)$ as per level of attachment. In nutshell, the expectant mothers had higher level of fetal attachment as compared to expectant fathers. There was a statistically significant difference between the two groups $(p=0.000)$.

This finding was also supported by a cross-sectional study conducted by Ustrunsz A et al, to compare the maternal and paternal fetal attachment in 144 Turkish couples. Findings revealed that MFA scores in pregnant women were significantly higher than PFA scores of their partners except unemployed partners. ${ }^{6}$ There was statistical significant difference between MFA and PFA scores $(\mathrm{p}=0.001)$.

In the present study, The association of maternal fetal attachment was found to be statistically significant with Gravida, parity, live birth, gender of previous child, planned pregnancy, history of infertility, method of conception and marital relationship as $(\mathrm{p}<0.05)$ except abortion, duration between marriage and conception and number of still births ( $\mathrm{p}>0.05)$. These findings were also supported by exploratory study conducted by Siddiqui A, on 171 pregnant women at third trimester of pregnancy. ${ }^{7}$ Results showed that maternal age, parity, partner relationship and a positive attitude towards pregnancy of both mother and her partner played an important role in prenatal attachment.

\section{CONCLUSION}

It was concluded that the expectant mothers had more fetal attachment than the expectant fathers. Partner relationship and a positive attitude towards pregnancy of both mother and her partner played an important role in prenatal attachment. Father should also educate and involved in pregnancy care to enhance prenatal attachment.

\section{ACKNOWLEDGMENTS}

Authors would like to thank to Mrs Mamta, Associate Professor, co- supervisor Mrs Nidhi Sagar, Professor, DMCH College of Nursing, Ludhiana for their valuable guidance and corporation during the study.

Funding: No funding sources

Conflict of interest: None declared

Ethical approval: The study was approved by the Institutional Ethics Committee

\section{REFERENCES}

1. Akbarzade M, Setodh S, Sharif F, Zare N. The effect of fathers' training regarding attachment skills on maternal-fetal attachments among Primigravida women. International $\mathbf{J}$ Comm Nurs Midwifery. 2014;(4):259-67.

2. Solchany JE. Promoting maternal mental health during pregnancy. 1st ed. Washington:NCAST;2001.

3. Mercer RT, Ferketich S, May K, DeJoseph J, Sollid D. Further exploration of maternal and paternal fetal attachment. Res Nurs Health. 1988;11(2):83-95.

4. Oppenheim D, Koren-Karie N, Sagi-Schwartz A. Emotion dialogues between mothers and children at 4.5 and 7.5 years: Relations with children's attachment at 1 year. Child development. 2007;78(1):38-52.

5. Lerum CW, LoBiondo-Wood G. The relationship of maternal age, quickening and physical symptoms of pregnancy to the development of maternal-fetal attachment. Birth. 1989;16:13-7. 
6. Ustrunsz A, Guvenc G, Akyuz A, Oflaz F. Comparison of maternal- and paternal- fetal attachment in Turkisk couples. Midwifery. 2010;26:e1-e9.

7. Siddiqui A, Hagglof B, Eisemann M. An exploration of prenatal attachment in Swedish expectant women. J Reprod Infant Psychol. 2007;17(4): 369-80.
Cite this article as: Kaur S, Mamta, Sagar N. Comparative study to assess the maternal and paternal fetal attachment among the expectant mothers and fathers. Int J Reprod Contracept Obstet Gynecol 2017;6:3134-7. 